\title{
Gastronomia sustentável: análise da logística reversa em restaurantes de Florianópolis, Brasil
}

\author{
Beatriz Ingryd Vasconcellos ${ }^{a}$ \\ Douglas Ricardo Vogel ${ }^{b}$ \\ Katarzyna Bortnowska Marinhoc
}

\begin{abstract}
Resumo
A logística reversa trata da recuperação e do gerenciamento de bens, podendo acrescentar valores para a imagem da empresa e o meio ambiente. Analisar o processo desta logística nas atividades dos restaurantes da Grande Florianópolis foi o objetivo deste trabalho. Os dados foram coletados de forma quantitativa através de um questionário aplicado a uma amostra não-probabilística de 24 estabelecimentos selecionados por conveniência, localizados em três rotas gastronômicas: Coqueiros, Sambaqui e Ribeirão da Ilha. Observou-se que os restaurantes têm práticas positivas e negativas para o meio ambiente sob o aspecto da logística reversa, sendo que os positivos tangem à reciclagem do óleo de cozinha, dos resíduos sólidos e a capacitação de colaborares. Já os negativos têm relação com a reutilização e reciclagem das embalagens, a falta de compostagem e o pequeno número de hortas nos restaurantes. Concluiu-se que a preocupação ambiental dos gestores é somente com o que já é exigido pela legislação e não uma filosofia da empresa. Observa-se a falta de incentivos e fiscalização governamental sobre os aspectos ambientais, assim como pesquisas acadêmicas em segmentos diferenciados.
\end{abstract}

Palavras-chave: Logística reversa; Gastronomia; Sustentabilidade; Restaurantes; Gestão ambiental.

\section{Abstract \\ Sustainable food: analysis of reverse logistics in Florianópolis restaurants, Brazil}

The reverse logistics deals with the recovery and the management of goods, being able to add values to an image of the company and environment. To analyze the logistics process in the activities of the restaurants of Greater Florianópolis for the purpose of this work. The data were collected quantitatively through a questionnaire applied to a non-probabilistic sample of 24 establishments selected for convenience, located in three gastronomic routes: Coqueiros, Sambaqui and Ribeirão da Ilha. It was observed that these are restaurants and practices that are positive and negative for the environment under the aspect of reverse logistics, and the positive ones are the recycling of cooking oil, solid waste and the Collaboration training. The negatives are related to reuse and recycling of packaging, a lack of composting and a small number of vegetable gardens in restaurants. It was concluded that the environmental concern of the managers is only a requirement of the legislation and not a philosophy of the company. It is observed the

\footnotetext{
a. Tecnóloga em Gastronomia pela Universidade Estácio de Florianópolis, Santa Catarina, Brasil. E-mail: beatriz.ingryd@gmail.com

b. Bacharel em Gastronomia pela Universidade Estácio de Florianópolis, Santa Catarina, Brasil. E-mail: vogel_tdb@hotmail.com

c. Mestre em Turismo e Hotelaria pela Universidade do Vale do Itajaí (UNIVALI). Docente na UNISUL e Faculdade Estácio de Florianópolis, Santa catarina, Brasil. E-mail: bortnowska@yahoo.com
} 
lack of incentives and governmental supervision on the environmental aspects, as well as academic research in differentiated segments.

Keywords: Reverse logistics; Gastronomy; Sustainability; Restaurants; Environmental management.

\section{Resumen}

Alimentaria sostenible: análisis de la logística inversa en restaurantes de Florianopolis, Brasil

La logística reversa trata de la recuperación y de la gestión de bienes, pudiendo añadir valores para una imagen de la empresa y medio ambiente. Analizar el proceso de logística en las actividades de los restaurantes de la Grande Florianópolis para el objetivo de este trabajo. Los datos fueron recolectados de forma cuantitativa a través de un cuestionario aplicado a una muestra no probabilística de 24 establecimientos seleccionados por conveniencia, ubicados en tres rutas gastronómicas: Coqueiros, Sambaqui y Ribeirão de la Isla. Se observó que son restaurantes y prácticas positivas y negativas para el medio ambiente bajo el aspecto de la logística reversa, siendo que los positivos tangen al reciclaje de aceite de cocina, de los residuos sólidos y de la Capacitación de empleados. Los negativos tienen relación con una reutilización y reciclaje de envases, una falta de compostaje y un pequeño número de huertas en los restaurantes. Se concluyó que la preocupación ambiental de los gestores es sólo una exigencia de la legislación y no una filosofía de la empresa. Se observa la falta de incentivos y fiscalización gubernamental sobre los aspectos ambientales, así como investigaciones académicas en segmentos diferenciados.

Palabras clave: Logística; Alimentos; Sostenibilidad; Restaurantes; Gestión ambiental inversa.

\section{INTRODUÇÃo}

Os restaurantes estão sendo cobrados pela sociedade no sentido de se adequarem a uma nova realidade de Produção Mais Limpa (PML), a fim de se manterem competitivos no mercado e serem sustentáveis. Uma das soluções é a denominada logística reversa (LR) (Chieregatto \& Claro, 2010).

Segundo Fernandes (2015), para que se tenha uma produção sustentável na gastronomia, é preciso envolver as questões relacionadas ao processo produtivo, o planejamento de cardápio, os fornecedores, a reciclagem e o gerenciamento dos resíduos.

Assim, a LR está comprometida com a recuperação e o gerenciamento de equipamentos, produtos, componentes e materiais. Este processo agrega, por exemplo, a simples revenda, o processo de remanufatura ou de reciclagem, e pode acrescentar valor em relação aos aspectos ambientais, competição de mercado e imagem corporativa (Costa \& Valle, 2006). A LR apresenta contribuições imensuráveis para vários setores que ainda não possuem este conhecimento, como o gastronômico. Chaves (2009, p. 19) afirmou que "não existem muitos estudos que abordem a operacionalização da logística reversa em alguns setores importantes da economia, como a indústria de alimentos". Santos, Loureiro e Oliveira (2013) consideram imprescindível o desenvolvimento de ações que estimulem 
empresas a serem responsáveis pelo fim da vida de seus produtos. Além disso, existe um número pequeno de pesquisas publicadas sobre gestão ambiental e sustentabilidade em restaurantes no Brasil (Gurgel, Carvalho, \& Salles, 2015), o que justifica a importância deste tipo de pesquisa para o setor gastronômico. Assim, este artigo visa analisar o processo reverso nas atividades de restaurantes de Florianópolis e propor ações aos gestores por meio da análise da situação atual.

0 artigo é caracterizado como uma pesquisa quantitativa de caráter exploratória, apoiada em pesquisa bibliográfica, para a qual ocorreu a elaboração de um questionário de 18 perguntas, que foi aplicado em 24 estabelecimentos diferentes em Florianópolis. Com os resultados da pesquisa foi possível analisar as características de cada rota gastronômica. Foram analisados os impactos positivos e negativos, correlacionando os resultados com as abordagens dos autores do referencial teórico.

\section{Referencial teórico}

\section{Logística reversa na gastronomia}

Para Gurgel et al. (2015), a falta de uma gestão ambiental adequada em restaurantes se deve não somente por desinteresse, mas pela falta de conhecimento desta e de seus benefícios. Consequentemente, as empresas não possuem informações suficientes para lidar com as decisões inerentes à prática deste processo, o que gera muitas incertezas. Para elucidar os principais temas ligados à logística reversa, o Quadro 1 faz a relação com os autores pesquisados.

Quadro 1 - Trabalhos encontrados sobre os temas pesquisados.

\begin{tabular}{|c|c|}
\hline TEMA & AUTORES (ANO) \\
\hline $\begin{array}{l}\text { Reutilização das } \\
\text { embalagens }\end{array}$ & $\begin{array}{l}\text { Siqueira (2002); Estival (2004); Costa \& Valle (2006); Castanho } \\
\text { (2006); Campos (2006); Adlmaier \& Sellitto (2007); Chaves (2009); } \\
\text { Chieregatto \& Claro (2010); Uda (2010); Cortez (2011); Souza (2011); } \\
\text { Lago (2013). }\end{array}$ \\
\hline $\begin{array}{l}\text { Reciclagem de } \\
\text { embalagens }\end{array}$ & $\begin{array}{l}\text { Estival (2004); Costa \& Valle (2006); Castanho (2006); Sousa, Leal \& } \\
\text { Soares (2006); Campos (2006); Adlmaier \& Sellitto (2007); Chaves } \\
\text { (2009); Uda (2010); Souza (2011); Cortez (2011); Nery, Conto, Zaro, } \\
\text { Pistorello \& Pereira (2013); Lago (2013); Gurgel, Carvalho \& Salles } \\
\text { (2015). }\end{array}$ \\
\hline $\begin{array}{l}\text { Óleo de cozinha } \\
\text { reciclado }\end{array}$ & $\begin{array}{l}\text { Schneider, Santos, Klamt \& Machado (2006); Silva (2008); Bilck, Silva, } \\
\text { Costa, Benassi \& Garcia (2009); Netto (2010); Rocha (2010); Zhang, } \\
\text { Wang \& Mortimer (2012); Silva et al. (2012); Zucatto, Welle \& Silva } \\
\text { (2013); Nery et al. (2013); Lago (2013); Acre \& Castilho (2013); } \\
\text { Kremer, Costa \& Mondo (2013); Oliveira (2014); Puntel \& Marinho } \\
\text { (2015); Gurgel et al. (2015). }\end{array}$ \\
\hline
\end{tabular}

(continua...) 
Quadro 1 - Continuação

\begin{tabular}{l|l}
\multicolumn{1}{c|}{ TEMA } & \multicolumn{1}{c|}{ AUTORES (ANO) } \\
\hline Resíduos sólidos & $\begin{array}{l}\text { Ribeiro (2002); Schneider et al. (2006); Silva (2008); Bilck et al. } \\
\text { (2009); Novaes \& Estival (2009); Chieregatto \& Claro (2010); Uda } \\
\text { (2010); Zucatto et al. (2013); Lago (2013); Nery et al. (2013); Kremer } \\
\text { et al. (2013); Acre \& Castilho (2013); Amaral, Costa, Corrêa \& Freitas } \\
\text { (2014); Puntel \& Marinho (2015); Fernandes (2015); Pistorello, Conto } \\
\text { \& Zaro (2015). }\end{array}$ \\
\hline $\begin{array}{l}\text { Produção de adubo } \\
\text { a partir dos resíduos } \\
\text { (compostagem) }\end{array}$ & $\begin{array}{l}\text { Venzke (2001); Siqueira (2002); Legaspe (2004); Silva (2008); Bilck } \\
\text { et al. (2009); Freeman (2011); Furtado \& Gadelha (2012); Lopes, Reis } \\
\text { \& Bezerra (2012); Nery et al. (2013); Acre \& Castilho (2013); Amaral } \\
\text { et al. (2014); Gurgel et al. (2015); Puntel \& Marinho (2015); Pistorello } \\
\text { et al. (2015). }\end{array}$ \\
\hline $\begin{array}{l}\text { Nowak (2004); Blyth \& Menagh (2006); Engelhard (2010); Freeman } \\
\text { (2011); MacRae et al. (2010); Gurgel et al. (2015); Puntel \& Marinho } \\
\text { restaurantes }\end{array}$ & $\begin{array}{l}\text { (2015). } \\
\text { Siqueira (2002); Ribeiro (2002); Estival (2004); Schneider et al. } \\
\text { (2006); Silva (2008); Bilck et al. (2009); Novaes \& Estival (2009); } \\
\text { Acre \& Castilho (2013); Kremer et al. (2013); Krause \& Bahls (2013); } \\
\text { Oliveira (2014); Puntel \& Marinho (2015). }\end{array}$ \\
\hline $\begin{array}{l}\text { Colabocitação de } \\
\text { Olares }\end{array}$ &
\end{tabular}

Fonte: Autores (2016)

É de conhecimento de ambientalistas, empresas e da sociedade em geral que a indústria constitui uma grande geradora de resíduos, o que acaba camuflando o setor da restauração e a sua responsabilidade social e ambiental (Gurgel et al. 2015). Como agravante, Silva (2008) considera que o termo "sustentável" está saturado e se tornou um rótulo para atividades questionáveis, com o objetivo de torna-las aceitáveis, dificultando a identificação dos estabelecimentos que a cumpram realmente.

A Produção Mais Limpa é considerada uma ferramenta da gestão ambiental que as empresas aplicam para serem mais responsáveis de forma social e ambiental (Filho \& Sicsú, 2003). Trata-se da aplicação de uma estratégia preventiva e aplicada em processos, produtos e serviços, com o objetivo de obter benefícios econômicos e sociais para as empresas, reduzindo riscos para a saúde e para o meio ambiente (United Nations Environment Programme, s.d).

Nesse sentido, Acre \& Castilho (2013) sugerem algumas atividades essenciais para o setor gastronômico ser considerado efetivamente sustentável. Estas atividades incluem a educação ambiental na capacitação de colaboradores, ter uma boa gestão de eficiência energética, procurar parcerias com produtores e fornecedores locais, optar pelo fortalecimento da marca através do Marketing Verde e procurar obtenção das certificações NBR ISO 9001:2015 (certifica sistemas de gestão de qualidade), ISO 14001:2015 (certifica sistemas da gestão ambiental) e a ISO 22000:2006 (certifica sistemas de gestão da segurança de alimentos).

Para Costa \& Valle (2002), por estar alinhada com a sustentabilidade, a logística reversa pode atuar e gerar benefícios de diversas formas: ao diminuir a descartabilidade, também abranda o consumo de matérias primas, o que, consequentemente, reduz o impacto ambiental. Como benefício à sociedade, a logística reversa ajuda na preservação do meio ambiente, na economia de energia e na geração de empregos. Para alcançar estes benefícios, torna-se necessário apro- 
fundar-se nos aspectos levantados pelos autores sobre a LR no Quadro 1, que são apresentados individualmente a seguir.

\section{Reutilização das embalagens}

Campos (2006) afirma que a embalagem não é mais considerada um mero recipiente que contém o produto. Está, na verdade, em constante evolução para responder de forma eficaz às exigências de todos os interventores. Por isso, integrar os aspectos ambientais no desenvolvimento das embalagens previne e minimiza impactos, além de possuir benefícios sociais. Para entender o impacto ambiental destas, deve-se primeiramente ter percepção dos três tipos de embalagens: descartáveis, reutilizáveis e retornáveis.

As embalagens descartáveis são utilizadas apenas uma vez. São pouco resistentes e responsáveis pela maior parte dos materiais descartados (Campos, 2006). Para Chiregatto \& Claro (2010, p. 101), estamos "na era dos descartáveis", onde "as embalagens de bebida e de alimentos passaram a ser produzidas em larga escala, substituindo os recipientes que até pouco tempo eram totalmente reutilizáveis, como as garrafas de vidro". Tais embalagens reutilizáveis são geralmente recebidas pelos fornecedores e podem ser reutilizadas de outras formas (Campos, 2006; Chieregatto \& Claro, 2010). Já as embalagens retornáveis são as que retornam à indústria e devem passar pelas etapas de transporte, lavagem e esterilização, tendo ainda certo impacto ambiental, porém, com um consumo menor de recursos naturais (Cortez, 2011). Para Costa \& Valle (2006), a aplicabilidade da LR é impulsionada por considerações/questões econômicas e ambientais, levando empresas a optarem pela utilização de embalagens retornáveis, por exemplo. Corroborando com isso, o estudo de Adlmaier \& Sellitto (2007) mostrou que o uso de embalagens retornáveis trouxe benefícios financeiros, redução de ataques ambientais e benefícios logísticos para a empresa exportadora pesquisada.

\section{Reciclagem de embalagens}

Para Cortez (2011) a reciclagem atua onde os materiais que seriam descartados, ou até mesmo os que já foram, são desviados, coletados, separados e processados com o objetivo de serem usados como matéria-prima na manufatura de bens. Já Castanho (2006, p. 49) considera que reciclar é "refazer o ciclo, trazer de volta à origem sob forma de matérias-primas, materiais que não se degradam facilmente e podem ser reprocessados mantendo as suas características básicas".

Uma parte importante do processo de reciclagem é a coleta seletiva. Para Sousa, Leal \& Soares (2006), quando esta é bem gerenciada, pode contrubuir de forma decisiva para o crescimento da eficiência da reciclagem. Para os autores, o processo de reciclagem somente deve ser utilizado se a recuperação dos resíduos for técnica e economicamente viável e higienicamente utilizável, além de considerar se as características de cada material são respeitadas.

A reciclagem beneficia todos os elos envolvidos: fornecedores, consumidores, governo, meio ambiente, comunidade, colaboradores e acionistas, além de apoiar uma mudança de atitude, valores e hábitos (Sousa et al. 2006). Cortez (2011) também afirma que a reciclagem acarreta em benefícios para o meio ambiente, 
pois permite que se poupe recursos naturas, água, energia e matéria prima, e para a sociedade, gerando emprego e renda com a venda dos recicláveis.

A reciclagem, a remanufatura e as embalagens reutilizáveis estão presentes tanto na logística reversa quanto na logística verde, uma vez que as duas atividades tratam do fluxo de retorno de produtos de pós-venda e a preocupação com a preservação do meio ambiente ao mesmo tempo (Adlmaier \& Sellito, 2007; Lago, 2013).

Vale lembrar que as particularidades de cada resíduo devem ser levadas em conta para definir se o elemento será reciclado, reutilizado ou retornado. É o exemplo das embalagens de produtos de limpeza, que podem ser reutilizadas, e das lâmpadas do estabelecimento, consideradas como resíduos perigosos e devem ter uma destinação separada (Domingues, 2013).

\section{Óleo de cozinha reciclado}

O óleo utilizado na fritura é considerado o maior e mais preocupante poluente gerado por estabelecimentos gastronômicos. Se não for descartado de forma correta, os prejuízos são quase imensuráveis: apenas um litro de óleo pode poluir cerca de um milhão de litros de água Além disso, pode entupir a rede de esgoto, causando prejuízos ao meio ambiente; quando despejado no rio, pode impedir a entrada de luz e oxigenação, prejudicando os animais marinhos; e em excesso forma uma camada de gordura nas margens da água, agravando o risco de enchentes (Abrasel, 2012; Acre \& Castilho, 2013; Silva et al. 2012; Bilck, Silva, Costa, Benassi \& Garcia, 2009).

A reciclagem do óleo acontece de forma diferenciada de outros produtos, e por isso necessita de um fluxo reverso diferente dos outros recicláveis. Para isso, é preciso "planejar e mapear toda a rota, buscando fazer a coleta em pontos próximos uns dos outros, de forma interligada e com quantidade suficiente para que essa atividade seja realizada de forma produtiva" (Oliveira, 2014, p.34).

Realizar o descarte correto do óleo residual acarreta em diversos benefícios para a sociedade e para o meio ambiente, reduz os custos em manutenção das redes de saneamento básico, minimiza efeitos da poluição e gera inclusão social pela rede de coleta (Rocha, 2010; Zucatto, Welle \& Silva, 2013).

Outra prática é a produção de sabão de forma caseira a partir do óleo de cozinha usado. Contudo, Netto (2010) e Oliveira (2014) não recomendam tal prática, uma vez que utiliza materiais corrosivos e é necessário seguir regras restritas para a produção. Por isso, existem entidades especializadas na coleta do óleo, fabricação do sabão e distribuição do produto de volta para os locais que forneceram o resíduo.

\section{Resíduos sólidos}

Segundo Acre \& Castilho (2013), existe uma grande problemática no meio gastronômico que é a quantidade de resíduos sólidos e o descaso, tanto governamental quanto dos empresários. Por esse motivo, autores enfatizam a importância de cumprir as legislações e seguir a Política Nacional de Resíduos Sólidos 
(PNRS) (Nery, Conto, Zaro, Pistorello \& Pereira, 2013; Amaral, Costa, Corrêa \& Freitas (2014); Lago, 2013; Fernandes, 2015).

A PNRS (lei no 12.305, de 2 de agosto de 2010) é formada pelo conjunto de princípios e ações definidas pelo Governo Federal a fim de aplicar uma gestão ambientalmente adequada aos resíduos sólidos, definidos pela lei como:

[...] material, substância, objeto ou bem descartado resultante de atividades humanas em sociedade, a cuja destinação final se procede, se propõe proceder ou se está obrigado a proceder, nos estados sólido ou semissólido, bem como gases contidos em recipientes e líquidos cujas particularidades tornem inviável o seu lançamento na rede pública de esgotos ou em corpos d'água, ou exijam para isso soluções técnica ou economicamente inviáveis em face da melhor tecnologia disponível (BRASIL, 2010)."

A logística reversa é considerada um dos instrumentos da PNRS, portanto também é uma das formas apontadas para que os geradores de resíduos possam cumprir com suas obrigações ambientais. Esta é definida no Cap. II, Art. 3ํㅡ, como um:

"[...] instrumento de desenvolvimento econômico e social caracterizado por um conjunto de ações, procedimentos e meios destinados a viabilizar a coleta e a restituição dos resíduos sólidos ao setor empresarial, para reaproveitamento, em seu ciclo ou em outros ciclos produtivos, ou outra destinação final ambientalmente adequada (BRASIL, 2010)."

A lei não possui especificações sobre restaurantes, mas define como geradores de resíduos sólidos "pessoas físicas ou jurídicas, de direito público ou privado, que geram resíduos sólidos por meio de suas atividades, nelas incluído o consumo" (BRASIL, Cap. 2, Art. 3, IX, 2010), abrindo margem para que setores não-industriais também possam ser responsáveis por seus resíduos.

Para minimizar o impacto ambiental e aproveitar subprodutos de forma eficaz, a pesquisa de Bilck et al. (2009) propôs aos responsáveis de restaurantes: incentivar a prática da reciclagem entre os colaboradores; estabelecer práticas para minimização da produção de resíduos; utilizar materiais recicláveis de menor impacto ambiental; estimular a consciência de preservação ambiental nos colaboradores; e estabelecer parcerias com Organizações não governamentais (ONG) ou particulares para coleta dos resíduos. Além disso, Chieregatto \& Claro (2010) consideram extremamente importante aprimorar a eficiência para diminuir, eliminar ou prevenir perdas.

Pistorello, Conto e Zaro (2015) enfatizam a importância de restaurantes realizarem o balanço de massa dos resíduos, ou seja, identificar a diferença entre a quantidade de alimentos utilizados no preparo e consumida com a quantidade de resíduos sólidos encontrados. Da mesma forma, Silva (2008) afirma que os restaurantes devem identificar os tipos de resíduos que contém nas sobras e os fatores que estão acarretando para que isto ocorra, a fim de reduzi-los e reaproveitá-los em outras preparações, ainda durante o pré-preparo. A análise do peso das sobras para cada composição é uma das formas apontadas para esta 
identificação, e com isso pode-se tomar medidas corretivas e exercer ações para otimizar os resultados (Ribeiro, 2002; Silva, 2008; Nery et al. 2013).

Novaes \& Estival (2009) afirmam que os gestores de restaurante podem receber benefícios financeiros e ganho na imagem corporativa em vender resíduos sólidos para cooperativas de catadores, mitigando custos de armazenamos e higienização dos resíduos.

\section{Produção de adubo a partir dos resíduos (compostagem)}

Para Amaral et al. (2014), restaurantes e cozinhas industriais são grandes geradores de resíduos, principalmente orgânicos, passíveis de serem reaproveitados. Legaspe (2004) afirma que a compostagem é a maneira mais simples e viável de tratar e reaproveitar estes resíduos.

Em Florianópolis, existe a Procomposto, uma empresa privada atuante desde novembro de 2014 na gestão dos resíduos dos restaurantes (Procomposto, s.d). As atividades da organização envolvem o transporte do resíduo; a pesagem do material e a entrega de um relatório de balanço; a disponibilização online de informações como data, horário, quantidade coletada e local da destinação dos resíduos; orientações aos colaboradores dos restaurantes sobre a correta separação e armazenamento do resíduo orgânico; e a transformação dos resíduos em adubo para compostagem.

Caso o restaurante não queira criar uma parceria com uma empresa privada para terceirizar a compostagem, os colaboradores podem ser orientados a separar os resíduos orgânicos corretamente, separando-os dos demais, para posterior compostagem. Esta prática necessita de cuidados de acondicionamento e transporte por causa do peso, da umidade e da perecibilidade do material. As soluções não são padronizadas, por isso o processo de armazenamento, coleta, transporte e destinação deve ser observado caso a caso (Amaral et al. 2014).

Para Freeman (2011), os benefícios da compostagem incluem abertura de vantagem competitiva, um fortalecimento dos laços com a comunidade local e é uma das razões para o restaurante ter sua própria horta.

\section{Horta em restaurantes}

Existem três tipos de horta, segundo Nowak (2004): o primeiro é o mais barato e simples, com as plantas em recipientes. 0 segundo consiste em transformar todo o telhado do restaurante na horta em si. Este processo exige um maior investimento, porém possui vantagens, como a retenção de água da chuva e construção de isolamento térmico e acústico do prédio; oferece habitat natural temporário para a fauna (como pássaros e borboletas) durante as suas migrações (Nowak, 2004); ajuda a salvar energia elétrica em termos de controle de temperatura; gera a possibilidade de criar diferentes cardápios de acordo com a sazonalidade; oferece uma aparência estética agradável e calma (Blyth \& Menagh, 2006); melhora a qualidade do ar; e ameniza impactos ambientais (Engelhard, 2010).

A terceira possibilidade levantada por Nowak (2004) é o cultivo de plantas hidropônicas, ou seja, plantas que não necessitam de solo, mas são plantadas em 
água com uma solução de nutrientes. Em termos de peso, esta opção é a mais leve das três, e oferece um crescimento mais rápido da horta.

Uma limitação que deve ser levada em consideração é a fertilidade do solo. Porém, as autoras Blyth \& Menagh (2006) afirmam que os restos de comida do restaurante podem ser uma das formas de contornar o problema, por meio da compostagem. As autoras também levam em consideração, no caso da horta em telhado, se a estrutura do estabelecimento é compatível com a quantidade de peso da produção, com o sistema de irrigação e a drenagem. Além de que, para prevenir que a água e as raízes comprometam o telhado, é importante ter uma membrana impermeável por baixo do solo da horta.

\section{Capacitação de colaborares}

O termo "educação ambiental" é discutido desde a Conferência de Estocolmo em 1972 (Siqueira, 2002), mas somente em 1999 foi instituída no Brasil a Política Nacional de Educação Ambiental. Esta incube todas as empresas, entidades de classe e instituições públicas e privadas a promoverem programas destinados à capacitação dos colaboradores, com vista de melhorias no ambiente de trabalho e a repercussão do processo produtivo no meio ambiente (BRASIL, 1999).

Consequentemente, para Krause \& Bahls (2013), colaboradores desmotivados ou despreparados que não atuam de maneira correta podem arruinar as políticas de sustentabilidade de um restaurante. A ocorrência constante de novos treinamentos, em função da alta rotatividade, contribui para um resultado negativo da capacitação. Desta forma, os colaboradores precisam receber incentivos a fim de terem uma percepção de carreira na gastronomia, uma vez que há baixa perspectiva de crescimento no ramo. Ribeiro (2002) considera que o trabalho dos colaboradores que atuam com produção de refeições pode ser considerado muitas vezes problemático pela falta de conhecimento técnico-operacional, sendo agravado pela falta de capacitação por parte dos gestores. Como solução, Krause \& Bahls (2013, p. 447), afirmam que:

Uma abordagem gerencial de incentivos em longo prazo tende a reverter a alta rotatividade e, em alguns casos, o descaso de membros da brigada de trabalho para com a qualidade prestada pelo empreendimento. No caso da sustentabilidade, esse aspecto tende a ser negligenciado por uma brigada despreparada, por tratar-se de um assunto novo e, muitas vezes, desconhecido à grande parte dos colaboradores da gastronomia (Krause \& Bahls, 2013, p. 447).

A pesquisa de Bilck et al. (2009) mostra a diferença entre um restaurante que investiu em capacitação adequada para os colaboradores e um que não o fez. No primeiro caso, percebeu-se que só havia empenho em recolher as latinhas de alumínio para a separação pelo seu valor monetário quando eram vendidas. Já no segundo restaurante, os colaboradores que receberam capacitação foram considerados bem conscientizados ecologicamente. 


\section{Metodologia}

A presente pesquisa é caracterizada como quantitativa, ou seja, traduz em números as informações a fim de classifica-las e analisa-las (Prodanov \& Freitas, 2013), de caráter exploratório, cuja fundamentação está baseada em pesquisa bibliográfica.

Um questionário com 18 perguntas fechadas e de múltipla escolha foi desenvolvido baseado nos autores apresentados no Quadro 1, e aplicado aos gerentes / responsáveis pelos estabelecimentos de três rotas gastronômicas distintas localizadas em Florianópolis. No bairro Coqueiros (chamado de B1) foram inquiridos nove restaurantes no dia 05/05/2016, em Sambaqui (considerado aqui como B2) foram sete questionários no dia 13/05/2016 e a terceira rota, Ribeirão da Ilha (identificado como B3) teve oito questionários aplicados no dia 16/06/2016. A escolha dos estabelecimentos se deu por amostragem não-probabilística, onde a seleção da população depende ao menos em parte do julgamento do pesquisador no campo (Mattar, 2014). A seleção da amostra foi realizada por conveniência a cargo de escolha do entrevistador (Malhotra, 2012), ficando aberta aos estabelecimentos que concordaram em participar da pesquisa, respondendo a um questionário estruturado, aplicado em formato de entrevista.

A pesquisa atingiu, no total, 24 estabelecimentos gastronômicos, sendo que $63 \%$, eram à lá carte, $9 \%$ panificadoras/confeitarias, $8 \%$ confeitarias, $8 \%$ de buffet, $4 \%$ "gelaterias", 4\% "hamburguerias", e outros $4 \%$ de venda de comida congelada. De acordo com Fonseca (2014), um restaurante à lá carte possui o formato de um restaurante tradicional, que possui um cardápio extenso, com preparações de aceitação geral. As confeitarias por sua vez, segundo o autor, podem vender doces como tortas e bolos e/ou produtos de panificação. Lippel (2002) cita os restaurantes de buffet com diversidade e rapidez, e o serviço realizado quase totalmente pelo próprio cliente. As "gelaterias", para Fonseca (2014), fazem parte dos restaurantes especializados, que dão ênfase à uma preparação específica, assim como as "hamburguerias", que oferecem um cardápio predominantemente de sanduíches e hambúrgueres, porém preparados com ingredientes de qualidade superior (Fonseca, 2014).

Os dados coletados foram organizados de acordo com os bairros e as perguntas realizadas e, então, analisados de acordo com as respostas para cada pergunta. De forma a simplificar a comparação dos dados de cada bairro para a análise de dados, foram elaborados quadros com a porcentagem individual e total da pesquisa.

\section{ANÁLISE dOS DADOS}

No questionário foi inquirido a respeito do conhecimento dos gestores sobre a logística reversa no setor gastronômico, cujos dados podem ser observados no Quadro 2. 
Quadro 2 - Você conhece a logística reversa na área da gastronomia?

\begin{tabular}{|c|c|c|c|c|}
\hline Resposta & B1 & B2 & B3 & Total \\
\hline Sim & $22 \%$ & $0 \%$ & $25 \%$ & $17 \%$ \\
\hline Não & $78 \%$ & $100 \%$ & $75 \%$ & $83 \%$ \\
\hline
\end{tabular}

Fonte: Autores, 2016

Percebe-se pelo Quadro 2 uma carência de conhecimentos sobre a logística reversa em todos os bairros, uma vez que apenas $17 \%$ dos restaurantes conheciam o termo, o que reforça a necessidade em conscientização ambiental dos responsáveis. Sobre isso, para Silva (2008), as empresas produtoras de bens e serviços consomem muitos recursos naturais não-renováveis, e a não conscientização de seus gestores acarreta num aumento ainda maior do impacto ambiental.

Outra explicação desta carência de conhecimentos sobre a logística reversa é consequente da afirmação de Soares, Streck, Trevisan \& Madruga (2016) de que a LR só começou a ganhar reconhecimento no Brasil recentemente, a partir da PNRS, e que ela ainda pode ser explorada de forma mais ampla.

Quadro 3 - Seus fornecedores utilizam algum tipo de embalagem retornável?

\begin{tabular}{|c|c|c|c|c|}
\hline Resposta & B1 & B2 & B3 & Total \\
\hline Sim & $33 \%$ & $43 \%$ & $75 \%$ & $50 \%$ \\
\hline Não & $67 \%$ & $57 \%$ & $25 \%$ & $50 \%$ \\
\hline
\end{tabular}

Fonte: Autores, 2016

Sobre as embalagens retornáveis, o Quadro 3 demonstra que especificamente no B1, o número de embalagens retornáveis é de apenas 33\%, um dado díspar dos 75\% encontrados no B3. Castanho (2006) considera a utilização de embalagens reutilizáveis e recicláveis uma tendência, uma vez que reduz custos e traz adequação às leis e ao mercado. A adequação para uma nova tendência de mercado não é rápida e homogênea, o que pode explicar a diferença apresentada nos dados de embalagens retornáveis entre o B1 o B3.

Quando os restaurantes da presente pesquisa foram inquiridos a respeito do tipo de embalagem que utilizavam, foi alegado que $88 \%$ são descartáveis, e 75\% delas não são reaproveitadas de nenhuma forma. Tanto no B1 quanto no B3, todos os restaurantes possuem embalagens descartáveis, enquanto no B2, apenas $57 \%$ dos restaurantes as utilizam.

Quadro 4 - Possui alguma parceria com alguma cooperativa que recicla óleo?

\begin{tabular}{|c|c|c|c|c|}
\hline Resposta & B1 & B2 & B3 & Total \\
\hline Sim & $67 \%$ & $100 \%$ & $87 \%$ & $85 \%$ \\
\hline Não & $33 \%$ & $0 \%$ & $13 \%$ & $15 \%$ \\
\hline
\end{tabular}

Fonte: Autores, 2016

Pelo Quadro 4 percebe-se que a maioria dos restaurantes de todos os bairros (85\%) possuem parceria com uma cooperativa que recicla o óleo de cozinha usado. Apenas no B1 este número foi inferior, com $67 \%$. Dos $15 \%$ do total que 
não têm parcerias com nenhuma cooperativa, o motivo dado por todos foi a falta de conhecimento ou de oferta por parte destas empresas. Os dados foram semelhantes aos encontrados na pesquisa de Chieregatto \& Claro (2010), onde 81\% dos restaurantes tinham parceria com uma cooperativa que trocava o óleo por produtos de limpeza, e também com a pesquisa de Silva (2008), na qual todos os restaurantes pesquisados alegaram ter dificuldades em destinar o óleo residual por falta de conhecimento das cooperativas existentes, e esta questão foi amenizada com o oferecimento deste serviço aos restaurantes.

Quadro 5 - Já foi realizada alguma produção a partir óleo de fritura?

\begin{tabular}{|l|l|l|l|l|}
\multicolumn{1}{|c|}{ Resposta } & \multicolumn{1}{c|}{ B1 } & \multicolumn{2}{c|}{ B2 } & \multicolumn{1}{c|}{ Total } \\
\hline Sabão & $33 \%$ & $71 \%$ & $70 \%$ & $58 \%$ \\
\hline Biodiesel & $0 \%$ & $0 \%$ & $20 \%$ & $8 \%$ \\
\hline Nenhum & $67 \%$ & $29 \%$ & $10 \%$ & $34 \%$ \\
\hline
\end{tabular}

Fonte: Autores, 2016

O Quadro 5 mostra que o óleo residual dos restaurantes é transformado em sabão pelas cooperativas em $58 \%$ dos casos, e $8 \%$ alegaram que era transformado em biodiesel. Do total, $34 \%$ não tinha conhecimento sobre a destinação final dada ao óleo pelas cooperativas.

Quadro 6- A região possui coleta seletiva de resíduos?

\begin{tabular}{|l|l|l|l|l|}
\multicolumn{1}{c|}{ Resposta } & \multicolumn{1}{c|}{ B1 } & \multicolumn{2}{c|}{ B2 } & \multicolumn{2}{c|}{ B3 } \\
\hline Sim & $100 \%$ & $71 \%$ & $87 \%$ & $88 \%$ \\
\hline Não & $0 \%$ & $29 \%$ & $0 \%$ & $8 \%$ \\
\hline Não sabe & $0 \%$ & $0 \%$ & $13 \%$ & $4 \%$ \\
\hline
\end{tabular}

Fonte: Autores, 2016

De acordo com a Prefeitura Municipal de Florianópolis (2015), os roteiros da coleta seletiva atendem $100 \%$ dos bairros da cidade e, mesmo assim, de acordo com o Quadro 6, no B2 29\% alegaram que o município não possuía o serviço, e no B3 13\% não tinham conhecimento.

Quando inquiridos sobre os resíduos do próprio estabelecimento, 96\% dos estabelecimentos inquiridos alegaram realizar separação, e apenas 13\% dos restaurantes do B3 não o fazem, totalizando apenas 4\% do total em Florianópolis. Dado parecido com a pesquisa de Silva (2008), onde 100\% dos inquiridos tinham interesse em destinar de forma correta os resíduos. Já na pesquisa de Chieregatto \& Claro (2010), 69\% dos restaurantes faziam divisão para o descarte, enquanto $31 \%$ não tinham uma organização que permita realizar a divisão.

Quadro 7 - Que tipo de separação realiza?

\begin{tabular}{|c|c|c|c|c|}
\hline Resposta & B1 & B2 & B3 & Total \\
\hline Papel/papelão & $15 \%$ & $9 \%$ & $16 \%$ & $13 \%$ \\
\hline Metal & $14 \%$ & $12 \%$ & $19 \%$ & $15 \%$ \\
\hline Vidro & $18 \%$ & $16 \%$ & $18 \%$ & $18 \%$ \\
\hline
\end{tabular}

(continua...) 
Quadro 7 - Continuação

\begin{tabular}{|c|c|c|c|c|}
\hline Resposta & B1 & B2 & B3 & Total \\
\hline Plástico & $14 \%$ & $19 \%$ & $13 \%$ & $15 \%$ \\
\hline Óleo & $14 \%$ & $19 \%$ & $18 \%$ & $18 \%$ \\
\hline Resíduos não recicláveis & $7 \%$ & $0 \%$ & $0 \%$ & $2 \%$ \\
\hline Orgânico & $14 \%$ & $22 \%$ & $13 \%$ & $17 \%$ \\
\hline Reciclado geral & $4 \%$ & $3 \%$ & $0 \%$ & $1 \%$ \\
\hline Outros & $0 \%$ & $0 \%$ & $3 \%$ & $1 \%$ \\
\hline
\end{tabular}

Fonte: Autores, 2016

No Quadro 7 é possível observar que o óleo residual, o vidro e os resíduos orgânicos são os mais separados pelos estabelecimentos. 0 dado é destoante com a pesquisa de Bilck et al. (2009), onde o empenho dos colaboradores dos restaurantes era maior em recolher latinhas de alumínio pelo seu valor de venda, se comparados com outros materiais menos valorizados.

Na presente pesquisa, quando inquiridos sobre o tipo de resíduo de forma individual, apenas $12 \%$ dos estabelecimentos possuíam uma noção superficial da quantidade gerada pelo restaurante, apesar de que nenhum realizava o balanço de massa total ou de cada elemento individual. A importância da pesagem é apresentada nos estudos de Silva (2008) e de Pistorello et al. (2015), os quais discutem, respectivamente, o objetivo de implementar ações de redução de desperdício e melhorar a produtividade e, ainda, a otimização de procedimentos no planejamento gastronômico e adoção de técnicas de reaproveitamento dos resíduos.

Sobre as sobras dos insumos nos restaurantes, 54\% são descartadas e 8\% dos estabelecimentos alegam não possuir quaisquer tipos de sobra. Daquilo que não vai diretamente para o descarte, $11 \%$ dos estabelecimentos destinam as sobras para a compostagem; outros $11 \%$ dão para moradores de rua, ainda que esta prática não esteja de acordo com a legislação; 8\% levam para fazendas que tem criação de porcos e aquicultura; e 4\% dos restaurantes fabricam o seu próprio detergente com o óleo residual. 0 baixo número de ações sobre a sobra dos alimentos é explicado por Silva (2008, p. 35), que alega em sua pesquisa que "como em geral as pessoas não identificam restos de alimento como geradores de impactos ambientais, a busca de soluções para o problema não é prioritária". Um dos motivos apontados para o desperdício de alimentos na pesquisa de Pistorello et al. (2015) num restaurante de um hotel no Rio Grande do Sul, foi devido à oferta de alimento ser muito maior do que o consumo, com o agravante da falta de um balanço mássico dos resíduos e de um planejamento de cardápio adequado, resultado principalmente de uma má gestão do estabelecimento. Sobre isso, os autores frisam que "contemplar a dimensão ambiental no planejamento das atividades gastronômicas é indiscutível para minimizar os impactos ambientais decorrentes dessa atividade" (p. 339). Para os autores, uma das formas de reduzir este impacto seria na destinação visando o reaproveitamento do insumo, como a compostagem. 
Quadro 8 - 0 restaurante faz compostagem dos insumos orgânicos?

\begin{tabular}{|c|c|c|c|c|}
\hline Resposta & B1 & B2 & B3 & Total \\
\hline Sim & $11 \%$ & $57 \%$ & $12 \%$ & $25 \%$ \\
\hline Não & $89 \%$ & $43 \%$ & $88 \%$ & $75 \%$ \\
\hline
\end{tabular}

Fonte: Autores, 2016

Observa-se pelo Quadro 8 que apenas um quarto dos restaurantes realizam a compostagem dos insumos orgânicos. Um número baixo, que condiz com a pequena quantidade de estabelecimentos que possuem horta, ou pretendem tê-la, como mostra o Quadro 9.

Quadro 9 - Há uma horta no local do restaurante?

\begin{tabular}{|c|c|c|c|c|}
\hline Resposta & B1 & B2 & B3 & Total \\
\hline Sim & $11 \%$ & $14 \%$ & $25 \%$ & $17 \%$ \\
\hline Não & $89 \%$ & $86 \%$ & $75 \%$ & $83 \%$ \\
\hline
\end{tabular}

Fonte: Autores, 2016

O Quadro 9 demonstra que 83\% dos restaurantes não possuem horta, e destes apenas $25 \%$ pretendem implementar uma futuramente. Dos que não planejam fazê-la, $67 \%$ alegaram como motivo o fato de não haver espaço; $9 \%$ não realizavam produção no local do restaurante; $8 \%$ afirmaram que usariam pouco; $8 \%$ não o fazem por causa da praia no local e outros $8 \%$ consideram possuir outras prioridades. A pesquisa de MacRae et al. (2010) também afirma que a falta de espaço é um dos fatores tipicamente assumidos para limitar a produção de alimento urbano. Porém, alternativas já estão se tornando populares pelo mundo, como a horta em telhados de hotéis e restaurantes (Nowak, 2004).

Quadro 10 - Realiza capacitação sobre educação ambiental e boas práticas?

\begin{tabular}{|c|c|c|c|c|}
\hline Resposta & B1 & B2 & B3 & Total \\
\hline Sim & $100 \%$ & $71 \%$ & $100 \%$ & $92 \%$ \\
\hline Não & $0 \%$ & $29 \%$ & $0 \%$ & $8 \%$ \\
\hline
\end{tabular}

Fonte: Autores, 2016

Vê-se pelo Quadro 10 que um total de $92 \%$ dos inquiridos alegam realizar algum tipo de capacitação em educação ambiental ou boas práticas de manipulação. Estes, em sua maioria (42\%), são realizados por uma empresa especializada, sendo $27 \%$ deles realizados fora da empresa. Em 15\% dos casos, nutricionistas que vão até o restaurante treinar os colaboradores, e em $16 \%$ é o próprio dono, gerente ou o chef de cozinha do estabelecimento que desempenha este papel. Dados contrastantes com a pesquisa de Kremer, Costa \& Mondo (2013), a qual mostrou que apenas 25\% dos 35 restaurantes em Florianópolis inquiridos, uma pequena parcela, realiza capacitação sobre a conscientização ambiental com um consultor especializado no assunto. 


\section{Mitigação dos impactos negativos e maximização dos positivos}

No Quadro 11 apresenta-se um levantamento dos temas abordados na pesquisa em conformidade com os autores do Quadro 1. Este elucida de forma ampla os impactos positivos e negativos encontrados.

Quadro 11 - impactos positivos e negativos da pesquisa

\begin{tabular}{|c|c|c|}
\hline TEMA & DADOS & IMPACTO \\
\hline $\begin{array}{l}\text { Reutilização das } \\
\text { embalagens }\end{array}$ & $\begin{array}{l}\text { Dos restaurantes que têm } \\
\text { embalagens, } 75 \% \text { não as reutilizam de } \\
\text { nenhuma forma. }\end{array}$ & Impacto negativo \\
\hline $\begin{array}{l}\text { Reciclagem das } \\
\text { embalagens }\end{array}$ & $\begin{array}{l}\text { A grande maioria, } 88 \% \text { utilizam } \\
\text { apenas embalagens descartáveis. }\end{array}$ & Impacto negativo \\
\hline $\begin{array}{l}\text { Óleo de cozinha } \\
\text { reciclado }\end{array}$ & $\begin{array}{l}\text { A maioria, } 83 \% \text { dos restaurantes } \\
\text { utilizam óleo de fritura no cardápio. } \\
\text { Destes, } 85 \% \text { dos possuem parceira } \\
\text { com alguma cooperativa que recicla } \\
\text { óleo. }\end{array}$ & Impacto positivo \\
\hline Resíduos sólidos & $\begin{array}{l}\text { 96\% dos restaurantes praticam a } \\
\text { separação de resíduos, apesar de } \\
\text { nenhum realizar a pesagem destes. }\end{array}$ & Impacto positivo \\
\hline $\begin{array}{l}\text { Produção de } \\
\text { adubo a partir } \\
\text { dos resíduos } \\
\text { (compostagem) }\end{array}$ & $\begin{array}{l}\text { A maioria dos restaurantes ( } 75 \% \text { ) não } \\
\text { faz qualquer tipo de compostagem } \\
\text { com as sobras dos alimentos. Como } \\
\text { agravante, mais da metade ( } 54 \% \text { ) } \\
\text { destas sobras vão para descarte. }\end{array}$ & Impacto negativo \\
\hline $\begin{array}{l}\text { Horta em } \\
\text { restaurantes }\end{array}$ & $\begin{array}{l}83 \% \text { dos estabelecimentos não } \\
\text { possuem horta, sendo o principal } \\
\text { motivo declarado a falta de espaço. } \\
\text { Apenas } 25 \% \text { tem interesse em plantar } \\
\text { uma futuramente. }\end{array}$ & Impacto negativo \\
\hline $\begin{array}{l}\text { Capacitação de } \\
\text { colaboradores }\end{array}$ & $\begin{array}{l}\text { 92\% dos colaboradores são treinados } \\
\text { de alguma forma sobre boas práticas e } \\
\text { educação ambiental. }\end{array}$ & Impacto positivo \\
\hline
\end{tabular}

Fonte: Autores, 2016

- Reutilização das embalagens/Reciclagem das embalagens: a maioria dos restaurantes utiliza embalagens descartáveis, gerando um impacto ambiental negativo. Estas poderiam ser reutilizadas ou recicladas, o que um número pequeno de estabelecimentos realiza. A política dos 3 R's da sustentabilidade (reduzir, reutilizar e reciclar) pode ser uma das formas para mitigar este impacto (Puntel \& Marinho, 2015). Outras soluções são levantadas pelos autores para a questão das embalagens, como o uso de embalagens retornáveis (Campos, 2006; Costa \& Valle, 2006; Adlmaier \& Sellito, 2007; Cortez, 2011) ou embalagens biodegradáveis (Castanho, 2006).

- Óleo de cozinha reciclado: Sobre o óleo de fritura, quase todos os restaurantes que possuem itens fritos no cardápio têm parceria com cooperativas que reciclam óleo, um aspecto muito positivo. Para maximizar a 
positividade deste dado, os restaurantes podem fazer uso dos produtos feitos com o óleo reciclado, como por exemplo a utilização do biodiesel nos veículos de delivery. Outra forma foi explorada na pesquisa de Puntel \& Marinho (2015), onde apenas 1\% dos restaurantes de Florianópolis utilizavam o sabão feito de óleo reciclado para lavar a louça, uma das propostas levantadas pelas autoras para redução do impacto ambiental.

- Produção de adubo a partir dos resíduos (compostagem): Apenas $25 \%$ dos restaurantes realizam ou possuem parceria com uma empresa de compostagem, um número pequeno em vista dos benefícios que podem ser alcançados na atividade. Como solução, Venzke (2001) sugeriu que as sobras orgânicas dos alimentos nos restaurantes não fossem mais vistas como resíduo, mas sim como matéria-prima nutritiva que pode ser reaproveitada para preparação de um novo produto por meio, por exemplo, da compostagem. Novaes \& Estival (2009) ainda apresentam a solução de doar estes alimentos para fazendas de animais.

- Horta em restaurantes: Entende-se que a falta de hortas nos restaurantes de Florianópolis seja uma consequência da falta de compostagem, já que o adubo produzido com as sobras poderia ser utilizado numa horta do próprio restaurante, com o objetivo de ter alimentos orgânicos locais e reduzir custos. Infelizmente pouquíssimos a possuem, ou planejam fazê-la. Blyth \& Menagh (2006) afirmam que se não existem meios do restaurante ter uma horta no telhado, uma ótima opção é o uso de recipientes, que dão menos trabalho, ocupam menor espaço e possuem o custo de mão de obra reduzido.

- Capacitação de colaboradores: A presente pesquisa constatou que a maior parte dos colaboradores recebe devida capacitação sobre boas práticas e manipulação e educação ambiental. Para Silva (2008), este é um dos fatores chave para evitar o desperdício de alimentos em restaurantes. 0 passo seguinte seria no incentivo em especialização, o que gera uma percepção de carreira e cria colaboradores mais técnicos, solução defendida pelos autores Krause \& Bahls (2013) para o restaurante ser sustentável e ter colaboradores capacitados e motivados.

\section{Conclusão}

A presente pesquisa alcançou seu objetivo de analisar a logística reversa dos restaurantes de Florianópolis. Com a pesquisa bibliográfica foi possível levantar definições do objeto principal, a logística reversa, bem como todos os temas relacionados com o processo reverso dos restaurantes, que foram aprofundados individualmente.

Conclui-se que são necessárias pesquisas acadêmicas que tratem da logística reversa em outros segmentos de mercado além da indústria, bem como se fazem importantes incentivos governamentais aos restaurantes para praticarem a LR. Vê-se também a necessidade de fiscalizar os parâmetros que já foram estabelecidos no PNRS a respeito da logística reversa e da gestão de resíduos.

Por parte dos gestores dos restaurantes, torna-se necessária uma maior conscientização sobre o uso e reciclagem de embalagens, sobre a gestão das sobras 
de comida e o seu reaproveitamento por meio da compostagem, que poderia ser utilizada ainda em uma horta do restaurante. A adaptação dos processos corporativos é refletida inclusive na manutenção da competitividade de mercado da organização, já que a discussão da temática é crescente (Spezamiglio, Galina \& Calia, 2016).

Em geral, percebeu-se alguma preocupação por parte da maioria dos gestores em sustentabilidade, porém apenas naquilo que já é exigido ou fiscalizado pela lei. Este processo de inserção nas organizações requer um alto esforço cognitivo de interpretação. Somente sistematicamente os envolvidos perceberão questões relacionadas à economia, à sociedade e ao meio ambiente (Nobre \& Ribeiro, 2013). Com esta pesquisa espera-se que os restaurantes se tornem mais responsáveis pelos seus resíduos e apliquem a gestão ambiental, especificamente a logística reversa de forma plena, como filosofia da empresa.

Entende-se que a contribuição da presente pesquisa para o estado-da-arte seja a exposição da relevância da percepção e das boas práticas que são realizadas. Esta contribuição evidencia a importância de que se estude com maior profundidade a aplicação da logística reversa no ramo gastronômico, com o intuito de conscientizar os gestores e colaboradores sobre investimento nos temas abordados.

\section{REFERÊNCIAS}

Abrasel (2012). Projeto Papa Óleo. Acesso em 2016, 8 de fevereiro, em http://www.abrasel.com.br/servicos/projeto-papa-oleo.html

Brasil. (1999). Política Nacional de Educação Ambiental. Lei no 9.795, de 27 de abril de 1999. Acesso em 2017, 23 de junho, em http://www.planalto.gov.br/ccivil_03/leis/ L9795.htm

Brasil. (2010). Política Nacional de Resíduos Sólidos. Lei no 12.305, de 2 de agosto de 2010. Acesso em 2017, 19 de junho, em http://www.planalto.gov.br/ccivil_03/_ato20072010/2010/lei/l12305.htm

Acre, D. M. \& Castilho, F. R. (2013). Gestão ambiental aplicada ao setor gastronômico: proposta para Dourados-MS. Revista Rosa dos Ventos, 5(2), 248-63.

Adlmaier, D. \& Sellitto, M. A. (2007). Embalagens retornáveis para transporte de bens manufaturados: um estudo de caso em logística reversa. Revista Produção, 17(2), 395406.

Amaral, D. A., Costa, J. R. C., Corrêa, A. C. \& Freitas, V. A.B. (2014). A compostagem como mecanismo de aproveitamento dos resíduos sólidos produzidos em restaurantes e cozinhas industriais no município do Rio Grande-RS, publicado no IX Simpósio Internacional de Qualidade Ambiental. Porto Alegre, 2014. RS: ABES.

Bilck, A. P., Silva, D. L. D., Costa G. A. N., Benassi, V. T. \& Garcia, S. (2009). Aproveitamento de Subprodutos: restaurantes de Londrina. Revista em Agronegócios e Meio Ambiente, 2(1), 87-104.

Blyth, A. \& Menagh, L. (2016). From rooftop to restaurant. The Canadian Organic Grower. Acesso em 2016, 12 de dezembro, em https://www.cog.ca/documents/RooftopRestaurantFA06.pdf 
Campos, T. (2006). Logística reversa: Aplicação ao Problema das Embalagens CEAGESP (Dissertação de Mestrado em Engenharia). Publicado pela Escola Politécnica da Universidade de São Paulo.

Castanho, S. C. R. (2006). Gerenciamento dos fluxos reversos: estudo de caso de uma indústria de embalagens de papelão ondulado (Dissertação de Mestrado em Administração). Publicado pela Universidade Metodista de Piracicaba.

Chaves, G. L. D. (2009). Logística reversa de pós-venda para alimentos derivados de carne e leite: análise dos retornos de distribuição (Dissertação de Mestrado em Engenharia de produção. Publicado pela Universidade Federal de São Carlos.

Chieregatto, C. M. P. \& Claro, J. A. C. S. (2010). Logística reversa em restaurantes comerciais na cidade de Santos. Revista da Micro e Pequena Empresa, 3(3), 96-110.

Cortez, A. T. C. (2011). Embalagens: o que fazer com elas?, publicado no XIII Encuentro de Geógrafos de América Latina, Costa Rica, 2011. Costa Rica: EGAL.

Costa, L. G. \& Valle, R. (2006). Logística reversa: importância, fatores para a aplicação e contexto brasileiro, publicado no III Simpósio de Excelência em Gestão e Tecnologia

Logística, Rio de Janeiro, 2006. RJ: SEGeT.

Domingues, A. C. R. (2013). Proposta de plano de gerenciamento de resíduos sólidos (PGRS) para um restaurant do município de Campo Mourão - PR (Trabalho de Conclusão de Curso em Engenharia Ambiental). Publicado pela Universidade Tecnológica Federal do Paraná.

Engelhard, B. (2010). Rooftop to tabletop: repurposing urban roofs for food production (Dissertação de Mestrado em Landscape Architecture). Publicado pela University of Washington.

Estival, K. G. S. (2004). Estudo do canal reverso de pós-consumo da embalagem de vidro em Recife/PE (Dissertação de Mestrado em Engenharia de Produção). Publicado pela Universidade Federal de Pernambuco.

Fernandes, E. C. S. (2015). Sustentabilidade na perspectiva do segmento gastronômico, publicado em XII ANPTUR: Política e Planejamento do Turismo, Natal, 2015. RN: ANPTUR.

Filho, J. C. G. S. \& Sicsú, A. B (2003). Produção Mais Limpa: uma ferramenta da Gestão Ambiental aplicada às empresas nacionais, publicado no XXIII Encontro Nac. de Eng. de Produção, Ouro Preto, 2003. MG: ENEGEP.

Florianópolis, Prefeitura Municipal. (2015). Plano municipal da coleta seletiva. Acesso em 2016, 25 de maio, em http://www.pmf.sc.gov.br/entidades/comcap/index.php?cms $=$ plano +

Fonseca, M. T. (2014). Tecnologias Gerenciais de Restaurantes. São Paulo, SP: SENAC.

Freeman, E. M. (2011). Restaurant industry sustainability: barriers and solutions to sustainable practice indicators (Dissertação de Mestrado em Science). Publicado pela Arizona State University.

Furtado, C. F. C. \& Gadelha M. A. C. (2012). Os impactos ambientais do consumo do coco verde na praia do futuro em Fortaleza-CE, publicado no IX Congresso Virtual Brasileiro Administração, São Paulo, 2012. SP: CONVIBRA.

Gurgel, L. M. D., Carvalho, R. G. \& Salles, M. C. T. (2015). As atividades de restaurantes de Mossoró, estado do Rio Grande do Norte, sob a perspectiva da gestão ambiental. Gestão \& Planejamento, 16(3), 438-56.

Krause, R. W. \& Bahls, A. A. D. S. M. (2013). Orientações gerais para uma gastronomia sustentável. Revista Turismo Visão e Ação - Eletrônica, 15(3), 434-50. 
Kremer, E. C., Costa, J. I. P. \& Mondo T. S. (2013). Análise das ações de responsabilidade ambiental implementadas nos restaurantes do centro de Florianópolis. Revista TURyDES, 6(14), 1-20.

Lago, S. M. S. (2013). Logística reversa, legislação e sustentabilidade: um modelo de coleta de óleo de fritura residual como matéria-prima para produção de biodiesel (Tese de Doutorado em Desenvolvimento Regional e Agronegócio), publicado pela Universidade Estadual do Oeste do Paraná.

Legaspe, L. R. (2004). 0 uso racional das sobras orgânicas urbanas na transformação alimentação humana, ração animal e adubo na CEAGESP São Paulo, publicado no Congresso brasileiro de ciência e tecnologia em resíduos e desenvolvimento sustentável, Costão do Santinho, 2004. SC: ICTR.

Lippel, I. L. (2002). Gestão de custos em restaurantes - utilização do método ABC (Dissertação de Mestrado em Engenharia de Produção). Publicado pela Universidade Federal de Santa Catarina.

Lopes, C. H. L., Reis, L. \& Bezerra, F. (2012). Modelo de gestão do processo de logística reversa no restaurante universitário da UFRA, publicado no VIII Simpósio Brasileiro de Sistemas de Informação, Paraty, 2012. RJ: SBSI.

MacRae, R., Gallanta, E., Patela, S., Michalak, M., Bunch, M. \& Schaffner, S. (2010). Could Toronto provide $10 \%$ of its fresh vegetable requirements from within its own boundaries? Matching consumption requirements with growing spaces. Journal of Agriculture, Food Systems, and Community Development, 1(2), 105-27.

Malhotra, N. (2012). Pesquisa de Marketing: uma orientação aplicada. Porto Alegre, RS: ARTMED.

Mattar, F. N. (2014). Pesquisa de marketing: metodologia, planejamento, execução e análi$s e$. Rio de Janeiro, RJ: ELSEVIER

Nery, C. H. C., Conto, S. M., Zaro, M., Pistorello, J. \& Pereira, G. S. (2013). Geração de Resíduos Sólidos em Eventos Gastronômicos: 0 Festiqueijo de Carlos Barbosa - RS. Revista Rosa dos Ventos, 5(2), 264-79.

Netto, R. C. (2010). Sustentabilidade de cadeias de reciclagem do óleo de fritura (Dissertação de Mestrado em Ciências Ambientais). Publicado pela Universidade de Taubaté.

Nobre, F. S. \& Ribeiro, R. E. M. (2013). Cognição e Sustentabilidade: Estudo de Casos Múltiplos no Índice de Sustentabilidade empresarial da BM\&amp;FBovespa. RAC - Revista de Administração Contemporânea, 17(4), 499-517.

Novaes, M. P. \& Estival, K. G. S. (2009). A logística reversa dos bares e restaurantes: a gestão dos resíduos sólidos dos estabelecimentos de Ilhéus, Bahia, Publicado no XXIX Encontro Nacional de Engenharia de Produção, Salvador, 2009. BA: ENEGEP.

Nowak, M. (2004). Urban agriculture on the rooftop (Senior Honors Thesis), publicado pela Cornell University.

Oliveira, R. B. (2014). Reciclagem de óleo de cozinha: análise de redes de coleta enfatizando experiências paulistas (Dissertação de Mestrado em Gestão Ambiental e Sustentabilidade). Publicado pela Universidade Nove de Julho.

Pistorello, J., Conto, S. M. \& Zaro, M. (2015). Geração de resíduos sólidos em um restaurante de um Hotel da Serra Gaúcha, Rio Grande do Sul, Brasil. Eng Sanit Ambient, 20(3), 337-346.

Procomposto. (s.d). Logística de resíduos orgânicos. Acesso em 2016, 7 de maio, em http://www.procomposto.com.br/\#!solucoes/c2sm 
Prodanov, C. C. \& Freitas, E. C. (2013). Metodologia do Trabalho Científico. Rio Grande do Sul, RS: Universidade Feevale.

Puntel, L. \& Marinho, K. B. (2015). Gastronomia e Sustentabilidade: uma análise da percepção da sustentabilidade ambiental em restaurantes buffet. Turismo em Análise, 26(3), 668-94.

Ribeiro, C. S. G. (2002). Análise de perdas em unidades de alimentação e nutrição (UANs) industriais: estudo de caso em restaurantes industriais (Dissertação de Mestrado em Engenharia de Produção. Publicado pela Universidade Federal de Santa Catarina.

Rocha, M., S. (2010). Análise da cadeia produtiva dos óleos de gordura residuais com foco nos agentes coletadores de resíduos urbanos: estudo de caso de Fortaleza (Dissertação de Mestrado em Logística e Pesquisa Operacional. Publicado pela Universidade Federal do Ceará.

Santos, C. A. F., Loureiro, M. G. \& Oliveira, T. S. (2013). A logística reversa e suas implicações na sustentabilidade: um estudo de caso de uma organização intermediária da cadeia reversa do ramo de sucatas. Revista Espacios, 34(5), 1.

Schneider, R. C. S., Santos, E., Klamt, R. A. \& Machado, E. L. (2006). Gestão do uso de óleos vegetais em restaurante visando a produção mais limpa, publicado no II Internacional Workshop Advances in Cleaner Production, São Paulo, 2006. SP: UNIP.

Silva, D. A. M., Paulino, M. S. M., Oliveira, C. A. L., Oliveira, F. P. F., Medeiros, J. B. S. \& Aquino, G. V. S. (2012). O reuso sustentável: a produção de sabão através do óleo de frituras, publicado no VII Congresso Norte Nordeste de Pesquisa e Inovação, Palmas, 2012. TO: CONNEPI.

Silva, S. D. (2008). Restaurantes: Estudo sobre o aproveitamento da matéria-prima e impactos das sobras no meio ambiente (Dissertação de Mestrado em Ciências Ambientais). Publicado pela Universidade de Taubaté.

Siqueira, L. C. (2002). Produção de resíduos no restaurante universitário: diagnósticos para ações de educação ambiental no Programa Agenda 21 da Universidade de Brasília (Dissertação de Mestrado em Ecologia). Publicado pela Universidade de Brasília.

Soares, I. T. D., Streck, L., Trevisan, M. \& Madruga, L. R. R. G. (2016). Logística reversa: uma análise de artigos publicados na base SPELL. Revista de Gestão Ambiental e Sustentabilidade, 5(2), 76-97.

Sousa, E. G., Leal, E. A. \& Soares M. A. (2006). Reciclagem e a sustentabilidade das cooperativas de trabalho: o caso da CORU, publicado no IX Simpósio de Administração da Produção, Logística e Operações Internacionais, São Paulo, 2006. SP: SIMPOI.

Souza, F. F. (2011). Proposta metodológica para aplicação de logística reversa de embalagens cartonadas no âmbito municipal (Dissertação de Mestrado em Meio Ambiente). Publicado pela Universidade Federal do Paraná.

Spezamiglio, B. S., Galina, S. V. R. \& Calia, R. C. (2016). Competitividade, inovação e sustentabilidade: uma inter-relação por meio da sistematização da literatura. Revista Eletrônica de Administração, 22(2), 363-393.

Uda, M. J. (2010). Logística reversa da reciclagem de garrafas pet em Curitiba (Dissertação de Mestrado em Desenvolvimento de Tecnologia e Meio Ambiente. Publicado pelo Instituto de Tecnologia para o Desenvolvimento.

United Nations Environment Programme. (s.d.). International declaration on cleaner production. Acesso em 2016, 16 de junho, em http://www.unep.fr/scp/cp/network/ pdf/english.pdf 
Venzke, C. S. (2001). A geração de resíduos em restaurantes, analisada sob a ótica da produção mais limpa, publicado no XXI Encontro Nacional de Engenharia da Produção, Salvador, 2001. BA: ENEGEP.

Zhang, H., Wang, Q. \& Mortimer, S. R. (2012). Waste cooking oil as an energy resource: Review of Chinese policies. Renewable and Sustainable Energy Reviews, 16(7), 5225-31.

Zucatto, L. C., Welle, I. \& Silva, T. N. (2013). Cadeia reversa do óleo de cozinha: coordenação, estrutura e aspectos relacionais. Revista de Administração de Empresas, 53(5), 442-53.

Recebido em: 02/03/2017

Aprovado em: 18/12/2017

\section{CONTRIBUiçÃo}

Beatriz Ingryd VAsconcellos: Desenvolvimento da pesquisa/artigo.

GDouglas Ricardo Vogel: Desenvolvimento da pesquisa/artigo.

Katarzyna Bortnowska Marinho: Desenvolvimento da pesquisa/artigo. 